\title{
Evaluation of Tp-e interval, Tp-e/QT ratio and index of cardiac-electrophysiological balance in patients with tinnitus
}

\author{
Hakan Kaya ${ }^{1}$, Arif Suner ${ }^{1 *}$, Mehtap Koparal ${ }^{2}$, S. Cem Yucetas ${ }^{3}$ and Safiye Kafadar ${ }^{4}$
}

\begin{abstract}
Background: Tinnitus is a common auditory symptom. Dysfunction in the autonomic nervous system (ANS) is an essential part of the etiopathogenesis of tinnitus. ANS regulates heart rate and heart rhythm and can lead to ventricular repolarization changes, which can cause malignant ventricular arrhythmias. T wave peak-to-end T(p-e) interval and $\mathrm{T}(\mathrm{p}-\mathrm{e}) / \mathrm{QT}$ ratio are known ventricular arrhythmia indexes, and the index of cardiac-electrophysiological balance (iCEB) is a novel index that can be used to predict the risk of malignant ventricular arrhythmia. The goal of the study was to investigate these ventricular arrhythmia indexes in patients with tinnitus.

Methods: The study population consisted of 240 patients with tinnitus and 240 healthy subjects. A standard 12-channel surface electrocardiogram was applied to both groups. T(p-e) interval, QT interval and QRS duration were determined. Corrected QT (QTc) was determined via Bazett's formula. To predict ventricular arrhythmia, iCEB (QT/QRS), $\mathrm{T}(\mathrm{p}-\mathrm{e}) / \mathrm{QT}$, corrected iCEB (QTc/QRS) and T(p-e)/QTc values were determined and compared between groups.

Results: Compared to the control group, QT (376.46 \pm 36.54 vs $346.52 \pm 24.51 \mathrm{~ms})$, QTc (426.68 $\pm 24.68 \mathrm{vs}$ $390.42 \pm 24.04 \mathrm{~ms}), \mathrm{T}(\mathrm{p}-\mathrm{e})(75.86 \pm 14.68 \mathrm{vs} 62.42 \pm 8.64 \mathrm{~ms}), \mathrm{T}(\mathrm{p}-\mathrm{e}) / \mathrm{QT}(0.201 \pm 0.06 \mathrm{vs} 0.180 \pm 0.01)$ and T(p-e)/QTc $(0.177 \pm 0.06$ vs $0.159 \pm 0.02)$ were significantly higher in patients with tinnitus ( $p<0.001$ for all). QT/QRS (3.92 \pm 0.68 vs $3.56 \pm 0.32)$ and QTc/QRS (4.44 \pm 1.03 vs $4.01 \pm 0.64)$ were also significantly higher in patients with tinnitus ( $p=0.018$ and $p=0.008$, respectively). In addition, significant positive correlations were found between $T(p-e), T(p-e) /$ QTc ratio and disease duration ( $r=0.792, p<0.001 ; r=0.500, p<0.001$, respectively).
\end{abstract}

Conclusion: As a result, patients with tinnitus may have an increased risk of malignant ventricular arrhythmia.

Keywords: Autonomic nervous system, Tinnitus, Ventricular arrhythmia

\section{Background}

Tinnitus is one of the most common otological symptoms [1]. It is known as the sensation of sound in the ear without an outer audible stimulus and is usually classified according to the duration of the disease. For example, tinnitus is classified as acute when the condition duration is less than three months, and chronic when it is more

\footnotetext{
*Correspondence: arifsuner@gmail.com

${ }^{1}$ Department of Cardiology, Adiyaman Training and Research Hospital, Adiyaman, Turkey

Full list of author information is available at the end of the article
}

than three months [2]. The mechanisms of cochlear and stress have been found to be involved in the etiopathogenesis of tinnitus [3]. The association between stress and tinnitus has been reported in a previous study, and stress is considered a risk factor for tinnitus [4]. The sympathetic branch of the autonomic nervous system (ANS) is related to stress, and its chronic form can also affect tinnitus [5]. A previous study suggested a positive correlation between sympathetic tone and distress related to tinnitus. In the same study, a negative correlation between parasympathetic tone and distress related to 
tinnitus was found [6]. Chronic tinnitus may be associated with chronic stress due to dysfunction of autonomic regulation [7].

ANS regulates the heart rate and heart rhythm. Dysfunction in the ANS might provoke alterations in ventricular repolarization and increase the risk of malignant ventricular arrhythmias. [8]. Many electrocardiogram (ECG) parameters have been used to predict ventricular arrhythmias. For instance, $\mathrm{T}$ wave peak-to-end $\mathrm{T}(\mathrm{p}-\mathrm{e})$ is used as an index of the transmural dispersion of repolarization (TDR), while $\mathrm{T}(\mathrm{p}-\mathrm{e}) / \mathrm{QT}$ ratio includes values of the transmural and spatial dispersion of repolarization. TDR is a potential indicator for ventricular arrhythmias [9-11]. Recently, the index of cardiac-electrophysiological balance (iCEB), which is calculated as QT interval divided by QRS duration (QT/QRS), was identified as a potential marker for anticipating drug-induced ventricular arrhythmias in an animal model [12]. Multiple studies suggested that $\mathrm{iCEB}$ can be used as a surrogate of cardiac wavelength, which in turn is an essential factor for ventricular arrhythmias susceptibility but can only be measured via invasive electrophysiology. It has been reported that iCEB might be a noninvasive and quickly assessable marker to identify the raised risk of arrhythmic in patients [13]. The goal of the present study was to evaluate ventricular arrhythmia indexes in patients with tinnitus.

\section{Methods}

\section{Study population and design}

This study was a single-centre prospective study. The study was conducted in the Department of Otorhinolaryngology-Head and Neck Surgery and the Department of Cardiology. The study was approved by the Adiyaman University Clinical Research Ethics Committee (approval number: 2021/01-27). Written informed consent was obtained from all the participants included in the study, and they were informed that participation was voluntary and they were free to withdraw from the research. The study was carried out according to the Helsinki Declaration. Adult outpatients referred to the Department of Otorhinolaryngology-Head and Neck Surgery for chronic subjective tinnitus in one ear or both ears participated in this study. The disease duration was recorded for each patient. The control group included healthy subjects who were admitted to the Cardiology Department for cardiological checkups. A total of 240 adult patients (above 18 years) with chronic tinnitus were included in the study, while the control group had 240 healthy volunteers who were above 18 years. Demographic information and blood pressure-related values were obtained from all the participants. Other measured variables included BMI (weight in kilograms divided by height in square meters), smoking status and creatinine, blood glucose, electrolyte and thyroid-stimulating hormone levels. Blood samples were collected during the participants' first clinical visit. Patients with left or right branch bundle block confirmed by electrocardiography, thyroid dysfunction, rheumatoid heart disease, cardiac valvular disease, chronic pulmonary disease, anaemia, electrolyte disorder, liver disease, acute or chronic infection, renal disease, atrioventricular conduction disorder, nonsinus rhythm confirmed by electrocardiography, systemic autoimmune disease as well as those using antidepressant, antipsychotic, antihistaminic or antiarrhythmic drugs were excluded from the study. In addition, patients with acute or stable coronary arterial disease, diabetes and hypertension and those using any drug that could affect sympathovagal activity were excluded from the study.

\section{Electrocardiographic and echocardiographic evaluation}

All the participants underwent a 12-lead ECG (Nihon Kohden, Tokyo, Japan) while resting in the supine state. The ECG was set to the paper speed of $50 \mathrm{~mm} / \mathrm{s}$ and calibrated such that $10 \mathrm{~mm}$ equals $1 \mathrm{mV}$. During the ECG recordings, all the participants had sinus rhythm. ECG data were used to assess the resting heart rate. ECG measurements of QRS duration, Tp-e intervals and QT intervals were calculated. Measurement errors were decreased by using a magnifying glass. Lead II and lead V5 was used for the measurements. The QT interval was named as the beginning of the QRS complex to the end of the $\mathrm{T}$ wave. The QT interval was corrected for heart rate via the Bazett formula: $\mathrm{QTC}=\mathrm{QT} \sqrt{ }(\mathrm{R}-\mathrm{R}$ interval $)$ [14]. Using these measurements, the values of the $\mathrm{T}(\mathrm{p}-\mathrm{e}) / \mathrm{QT}$, $\mathrm{T}(\mathrm{p}-\mathrm{e}) / \mathrm{QTc}, \mathrm{QT} / \mathrm{QRS}$ (iCEB) and QTc/QRS (corrected iCEB [iCEBc]) were assessed.

A Vivid 5 (General Electric, Horten, Norway) was used for transthoracic echocardiography examination with a $2.5 \mathrm{MHz}$ transducer. The patients were made to lie on their left side to perform the imaging process using standard techniques according to the guidelines [15] and were monitored throughout the imaging process. The Simpson method was used to calculate the left ventricle ejection fraction (LVEF) [16].

\section{Statistical analysis}

For the statistical analyses, SPSS 22.0 software program (SPSS Inc., Chicago, IL, USA) was used. Continuous variables were presented as mean \pm standard deviation and categorical variables as numbers and percentages. Independent sample t-tests were used to compare continuous variables, while the Mann-Whitney U test was used for the noncontinuous parametric variables. The distribution of the data was evaluated using the Kolmogorov-Smirnov test. Categorical variables were compared 
within the study group using the chi-square test. Pearson's correlation test was used for correlational analysis, and $\mathrm{p}$-value $<0.05$ was considered statistically significant.

\section{Results}

The present study consisted of 240 patients with tinnitus (144 males; mean age $=47.82 \pm 8.53$ years $)$ and 240 healthy controls (156 males; mean age $=46.54 \pm 5.32$ years). The clinical characteristics, echocardiographic and laboratory data of the participants are presented in Table 1. There were no significant differences in terms of gender, age, smoking status, BMI, diastolic and systolic blood pressure, LVEF and creatinine, potassium, calcium, magnesium, fasting glucose and thyroid-stimulating hormone levels between the two groups ( $\mathrm{p}>0.05$ for all).

The electrocardiographic findings of the two groups are presented in Table 2. The mean heart rate and QRS duration were similar between the patients and the control group $(76.24 \pm 10.02$ vs $77.32 \pm 10.26$ beats/ $\min , \quad \mathrm{p}=0.624 ; \quad 96.04 \pm 18.72$ vs $97.24 \pm 12.32 \mathrm{~ms}$, $\mathrm{p}=0.565$, respectively). Compared to the control group, QT $(376.46 \pm 36.54$ vs $346.52 \pm 24.51 \mathrm{~ms})$, QTc $(426.68 \pm 24.68$ vs $390.42 \pm 24.04 \mathrm{~ms}), \quad \mathrm{T}(\mathrm{p}-$ e) $(75.86 \pm 14.68$ vs $62.42 \pm 8.64 \mathrm{~ms}), \mathrm{T}(\mathrm{p}-\mathrm{e}) /$ QT $\quad(0.201 \pm 0.06$ vs $0.180 \pm 0.01)$ and $\mathrm{T}(\mathrm{p}-\mathrm{e}) / \mathrm{QTc}$ $(0.177 \pm 0.06$ vs $0.159 \pm 0.02)$ were higher in patients with tinnitus ( $\mathrm{p}<0.001$ for all). QT/QRS $(3.92 \pm 0.68$ vs $3.56 \pm 0.32)$ and QTc/QRS $(4.44 \pm 1.03$ vs $4.01 \pm 0.64)$ were significantly higher in patients with tinnitus $(\mathrm{p}=0.018$ and $\mathrm{p}=0.008$, respectively). A significant
Table 2 Electrocardiographic findings of the groups

\begin{tabular}{lccr}
\hline & $\begin{array}{l}\text { Patients } \\
\text { with tinnitus } \\
(\mathbf{n = 2 4 0 )}\end{array}$ & $\begin{array}{l}\text { Control group } \\
(\mathbf{n = 2 4 0 )}\end{array}$ & p-value \\
\hline $\begin{array}{l}\text { Heart rate (beats/ } \\
\text { min) }\end{array}$ & $76.24 \pm 10.02$ & $77.32 \pm 10.26$ & 0.624 \\
QRS (ms) & $96.04 \pm 18.72$ & $97.24 \pm 12.32$ & 0.565 \\
QT interval (ms) & $376.46 \pm 36.54$ & $346.52 \pm 24.51$ & $<0.001$ \\
QTc interval (ms) & $426.68 \pm 24.68$ & $390.42 \pm 24.04$ & $<0.001$ \\
Tp-e interval (ms) & $75.86 \pm 14.68$ & $62.42 \pm 8.64$ & $<0.001$ \\
Tp-e/QT ratio & $0.201 \pm 0.06$ & $0.180 \pm 0.01$ & $<0.001$ \\
Tp-e/QTc ratio & $0.177 \pm 0.06$ & $0.159 \pm 0.02$ & $<0.001$ \\
iCEB (QT/QRS) & $3.92 \pm 0.68$ & $3.56 \pm 0.32$ & 0.018 \\
iCEBC (QTc/QRS) & $4.44 \pm 1.03$ & $4.01 \pm 0.64$ & 0.008 \\
\hline
\end{tabular}

QTC corrected QT interval, Tp-e T wave peak-to-end, iCEB index of cardioelectrophysiological balance, iCEBc corrected iCEB

positive correlation was found between $\mathrm{T}(\mathrm{p}-\mathrm{e})$ and disease duration $(r=0.792, p<0.001)$ (Fig. 1$)$. In addition, a significant positive correlation was found between $\mathrm{T}(\mathrm{p}$ e)/QTc ratio and disease duration $(\mathrm{r}=0.500, \mathrm{p}<0.001)$ (Fig. 2).

\section{Discussion}

In the present study, QT, QTc, $\mathrm{T}(\mathrm{p}-\mathrm{e}), \mathrm{T}(\mathrm{p}-\mathrm{e}) / \mathrm{QT}, \mathrm{T}(\mathrm{p}-$ e)/QTc, iCEB and iCEBc parameters were significantly higher in patients with tinnitus when compared to the control group. In addition, significant positive correlations were found between $\mathrm{T}(\mathrm{p}-\mathrm{e}), \mathrm{T}(\mathrm{p}-\mathrm{e}) / \mathrm{QTc}$ ratio and the disease duration. These results point out a potential

Table 1 Clinical characteristics, laboratory and echocardiographic findings of the groups

\begin{tabular}{|c|c|c|c|}
\hline & Patients with tinnitus $(n=240)$ & Control group $(n=240)$ & p-value \\
\hline Age (years) & $47.82 \pm 8.53$ & $46.54 \pm 5.32$ & 0.137 \\
\hline Gender, male, n \% & $144(60)$ & $156(65)$ & 0.538 \\
\hline $\mathrm{BMI}\left(\mathrm{kg} / \mathrm{m}^{2}\right)$ & $26.73 \pm 2.34$ & $25.82 \pm 2.68$ & 0.098 \\
\hline $\begin{array}{l}\text { Smokers, } n,(\%) \\
\text { Disease duration (years) }\end{array}$ & $\begin{array}{l}96(40) \\
5.32 \pm 2.4\end{array}$ & $84(35)$ & 0.528 \\
\hline Systolic BP (mmHg) & $124.62 \pm 5.23$ & $123.46 \pm 4.65$ & 0.812 \\
\hline Diastolic BP (mmHg) & $72.64 \pm 4.04$ & $71.43 \pm 5.06$ & 0.526 \\
\hline IVS (mm) & $10.52 \pm 0.68$ & $10.21 \pm 0.54$ & 0.396 \\
\hline $\mathrm{PW}(\mathrm{mm})$ & $8.22 \pm 1.23$ & $8.04 \pm 1.12$ & 0.256 \\
\hline LVEF (\%) & $61.46 \pm 3.27$ & $61.87 \pm 2.86$ & 0.196 \\
\hline Creatinine (mg/dL) & $0.86 \pm 0.23$ & $0.83 \pm 0.21$ & 0.364 \\
\hline Potassium (mmol/L) & $4.32 \pm 0.21$ & $4.26 \pm 0.41$ & 0.498 \\
\hline Calcium (mg/dL) & $9.62 \pm 0.46$ & $9.70 \pm 0.48$ & 0.594 \\
\hline Magnesium (mg/dL) & $2.01 \pm 0.32$ & $2.12 \pm 0.28$ & 0.232 \\
\hline Fasting glucose (mg/dL) & $98.74 \pm 11.64$ & $92.72 \pm 12.23$ & 0.168 \\
\hline Thyroid stimulating hormone $(\mu \mathrm{U} / \mathrm{mL})$ & $2.32 \pm 1.21$ & $2.58 \pm 1.14$ & 0.065 \\
\hline
\end{tabular}




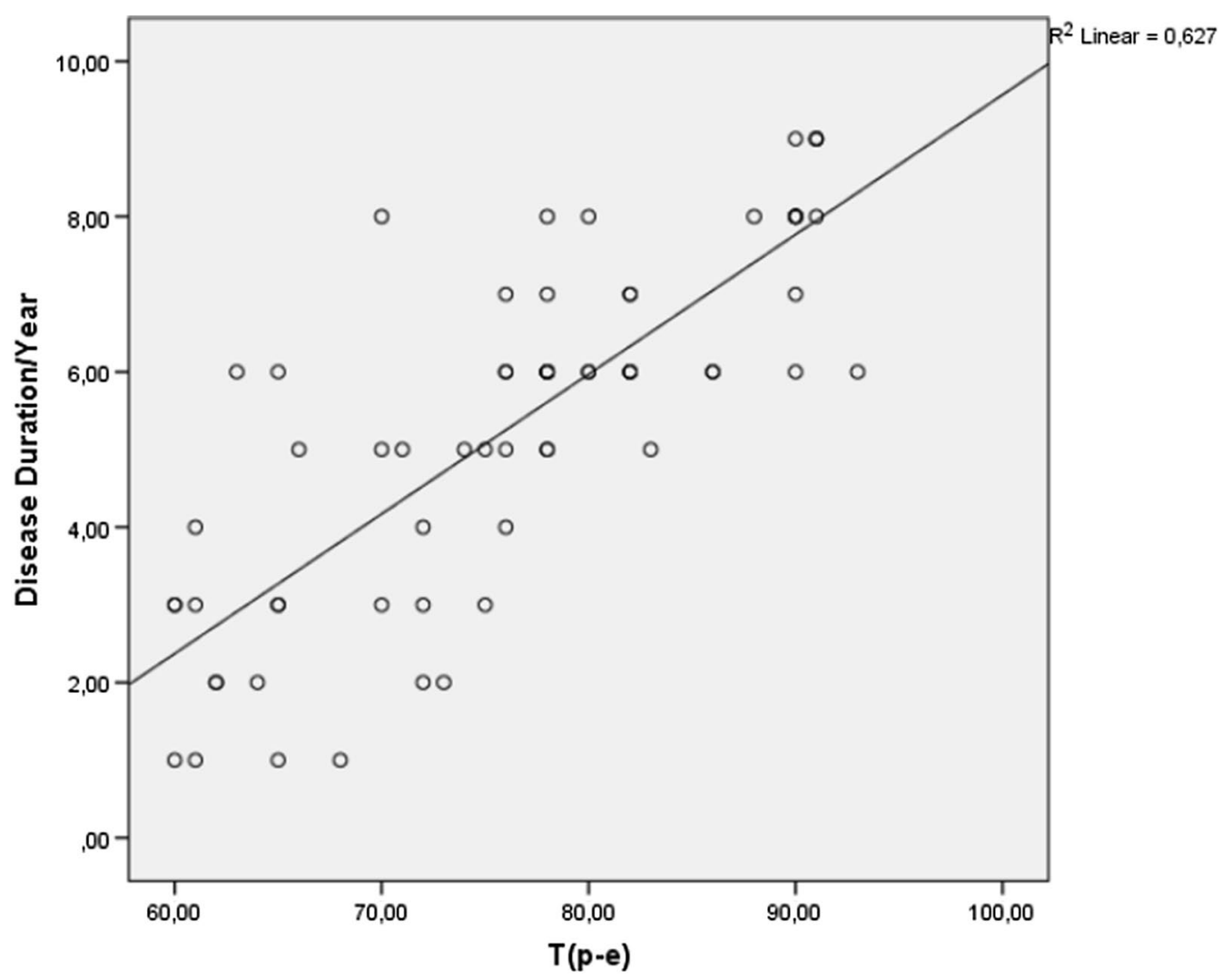

Fig. 1 Correlations between T(p-e) interval and disease duration

increased risk of malignant ventricular arrhythmias in patients with tinnitus. To the best of our knowledge, no study has examined these parameters to evaluate the risk of malignant ventricular arrhythmias in patients with tinnitus in the literature.

Tinnitus is known as the sensation of sound in the ear without an outer audible stimulus [17]. The etiopathogenesis of tinnitus is not only associated with the cochlear mechanisms but also with stress. Current pathophysiological models link the initiation and maintenance of tinnitus with stress $[18,19]$. In addition, studies have shown that stress is an effective factor that can turn mild tinnitus into a severe one [20]. The sympathetic branch of the ANS plays a major role in stress [21]. ANS also plays a major role in the development of ventricular arrhythmias, as it is a major modulator of ventricular repolarization. Several mechanisms linking ANS dysfunction and ventricular arrhythmias are very well established, albeit some details are still to be unravelled [22]. Methods such as hormonal mediator tests, pharmacological tests and various psychological stress tests could be used to evaluate ANS functions. One of these methods is heart rate variability (HRV), which is controlled by sympathetic and parasympathetic cardiac nerves. While sympathetic activity increases heart rate, parasympathetic activity decreases heart rate. HRV studies have also improved our knowledge of the effects of physiological events on tinnitus. It has been found that parasympathetic activity and sympathetic activity can be assessed using HRV parameters. The association between ANS dysfunction and cardiac autonomous dysfunction has been investigated in many studies through using HRV. A previous study showed an increase in sympathetic activity in patients with rheumatoid arthritis using HRV parameters and reported that this might cause malignant ventricular arrhythmias [23]. Patients with systemic lupus erythematosus have been found to have abnormal HRV, which reflected increased sympathetic activity and cardiac autonomic dysfunction [24]. Choi et al. evaluated HRV parameters in patients with tinnitus and demonstrated that sympathetic activity increased in these patients [25]. They also observed a positive correlation of the tinnitus period with sympathetic activity [25]. Another study that investigated the relationship between neural activity and the severity of tinnitus showed a positive correlation between sympathetic markers and tinnitus distress, and a negative correlation between tinnitus distress and parasympathetic markers [26]. Betz et al. observed that HRV 


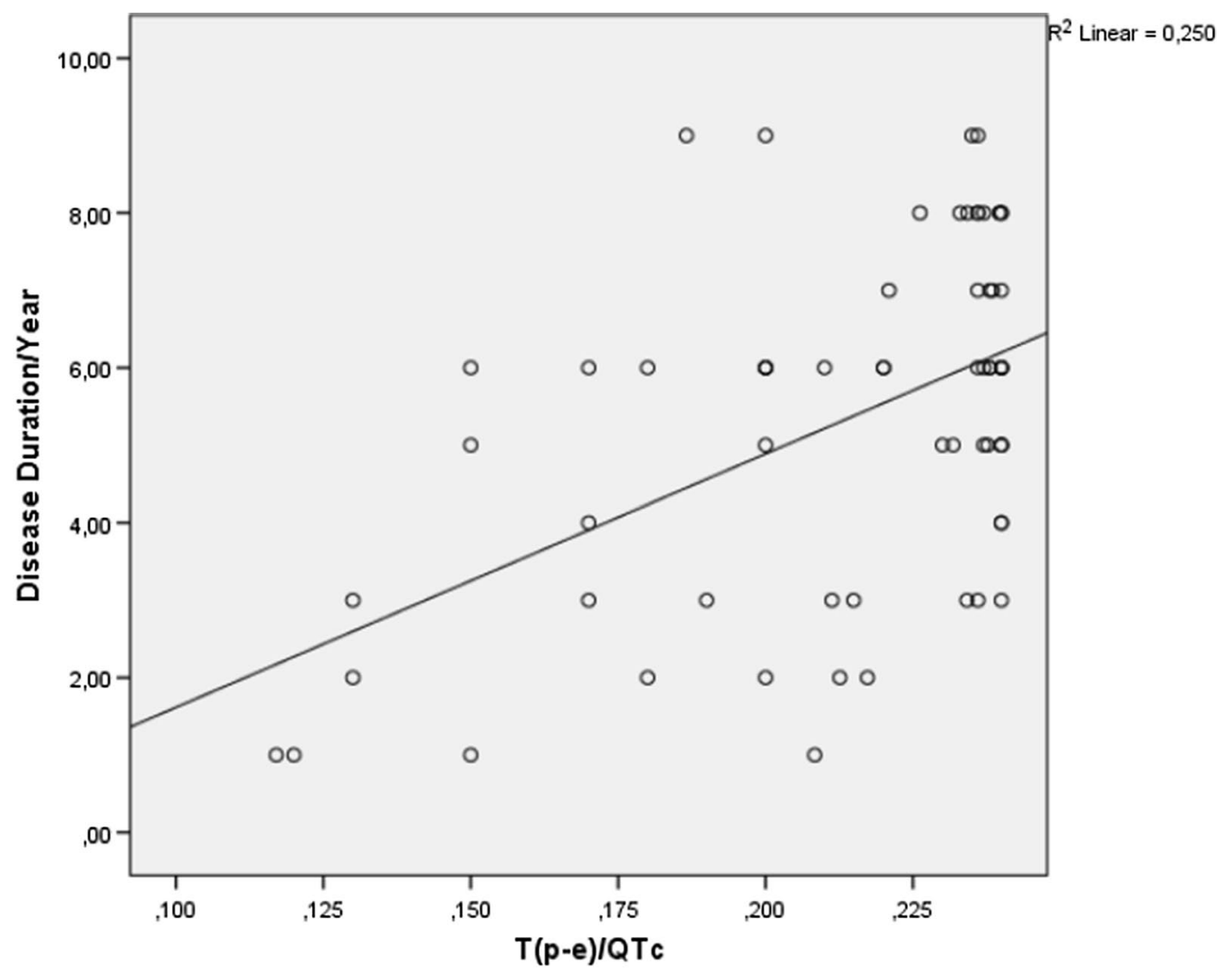

Fig. 2 Correlations between T(p-e)/QTc ratio and disease duration

parameters were similar between patients with tinnitus and the healthy control group. However, subjectively, they reported an increased level of tinnitus after exposure to stress in the same study [27]. HRV measurements are complex and quite different, as different researchers measure different time units, evaluation and comparison using the obtained data may give inaccurate outcomes [28].

$\mathrm{T}$ wave represents ventricular repolarization at ECG. $\mathrm{T}$ (p-e) interval has been used as an index of the TDR. HRV assesses the sympathetic-parasympathetic balance at the sinus node level, while measures of ventricular repolarization are influenced, among other factors, by the sympathetic-parasympathetic balance at the ventricular level. Parameters such as T(p-e)/QT and T(p-e)/ QTc ratios, which are sensitive, have recently been used to predict ventricular repolarization dispersion [29, 30]. An increase in $\mathrm{T}(\mathrm{p}-\mathrm{e}) / \mathrm{QT}$ ratio and $\mathrm{T}(\mathrm{p}-\mathrm{e})$ interval has been reported in various cardiac diseases such as Brugada, long QT and short QT syndromes, and noncardiac diseases such as autoimmune hepatitis, psoriasis and obstructive sleep apnoea [30-33]. Lecca et al. reported that QTc was prolonged among workers operating at a site where stress level was found to be elevated and suggested that work-related stress had subclinical effects on the cardiac function autonomic regulation [34]. Afsin et al. indicated that the $\mathrm{T}(\mathrm{p}-\mathrm{e}) / \mathrm{QT}$ ratio and $\mathrm{T}(\mathrm{p}-\mathrm{e})$ interval increased among patients with panic disorder and suggested that this might be due to the dysfunction of ANS through elevated sympathetic activity [35]. Similarly, it has been reported that $\mathrm{T}(\mathrm{p}-\mathrm{e})$ and $\mathrm{T}(\mathrm{p}-\mathrm{e}) / \mathrm{QT}$ values increased in patients with gastroesophageal reflux disease, which might be due to increased sympathetic activity [36]. A previous study reported that tinnitus is associated with sleep deprivation, emotional difficulties and social interaction problems [37]. A positive correlation has been reported between sleep deprivation and $\mathrm{T}(\mathrm{p}-\mathrm{e}) / \mathrm{QT}$ and $\mathrm{T}(\mathrm{p}-\mathrm{e})$ values [38]. Our results showed a significant increase in $\mathrm{T}(\mathrm{p}-\mathrm{e})$ and $\mathrm{T}(\mathrm{p}-\mathrm{e}) / \mathrm{QT}$ values in patients with tinnitus and this might be due to the dysfunction of ANS through elevated sympathetic activity, which is consistent with previous studies.

$\mathrm{iCEB}$ is a noninvasive parameter used to estimate the risk of ventricular proarrhythmia. iCEB may offer knowledge for both repolarization and depolarisation of the cardiac action potential. Such a feature may estimate the cardiac proarrhythmia risk better than $\mathrm{T}$ wave with repolarization only, TDR and QT interval variability. There 
are few studies on iCEB in the literature. Nafakhi et al. demonstrated that an increase in $\mathrm{ICEB}$ was related to the raised pericardial fat volume in patients with suspected coronary artery disease [39]. Yumurtaci et al. demonstrated that patients with acute myocarditis who had arrhythmia had higher levels of iCEB, T(p-e), T(p-e)/QTc and $\mathrm{T}(\mathrm{p}-\mathrm{e}) / \mathrm{QT}$ than those without arrhythmia [40]. Our study showed that $\mathrm{iCEB}$ and $\mathrm{iCEB}$ c values were significantly higher in patients with tinnitus compared to the control group. In our study, the larger values of iCEB and $\mathrm{iCEBc}$ observed in the patients versus the controls mostly reflect the longer QTc value (no differences were found in QRS duration).

\section{Study limitations}

The major limitations of the present study are the small number of samples, the use of only one study centre and the lack of follow-up of patients for ECG changes, sudden cardiac death or malignant ventricular arrhythmia.

\section{Conclusion}

Our result revealed that QT, QTc, T(p-e), T(p-e)/QT, $\mathrm{T}(\mathrm{p}-\mathrm{e}) / \mathrm{QTc}$ iCEB and iCEBc values were significantly higher in patients with tinnitus compared to the healthy group. In addition, significant positive correlations were found between $\mathrm{T}(\mathrm{p}-\mathrm{e}), \mathrm{T}(\mathrm{p}-\mathrm{e}) / \mathrm{QTc}$ ratio and disease duration. According to our results, patients with tinnitus may have an increased risk of malignant ventricular arrhythmias. Further studies with follow-up are needed to validate our findings.

\begin{abstract}
Abbreviations
ANS: Autonomic nervous system; BMI: Body mass index; T(p-e): T wave peakto-end; iCEB: Index of cardiac-electrophysiological balance; iCEBc: Corrected index of cardiac-electrophysiological balance; QTc: Corrected QT interval; ECG: Electrocardiogram; TDR: Transmural dispersion of repolarization; LVEF: Left ventricle ejection fraction; HRV: Heart rate variability; BP: Blood pressure; IVS: Interventricular septum; PW: Posterior wall.
\end{abstract}

\section{Acknowledgements}

None

\section{Authors' contributions}

$H K, A S$ and MK collected data and designed the study. The manuscript was revised by HK, AS, MK, SCY and SK. The manuscript was written by HK, AS and MK. All authors read and approved the final manuscript.

\section{Funding}

No funding was obtained for this study.

\section{Availability of data and materials}

The datasets used and analysed during the current study are available from the corresponding author upon reasonable request.

\section{Declarations}

Ethics approval and consent to participate

The study was performed after the approval of the Adıyaman University Clinical Research Ethics Committee was obtained. Written informed consent was gotten from all the participants included in the study, and they were informed that participation was voluntary and they were free to withdraw from the research. The study was carried out according to the Helsinki Declaration.

\section{Consent for publication}

Not applicable.

\section{Competing interests}

The authors declare that they have no competing interests.

\section{Author details}

${ }^{1}$ Department of Cardiology, Adiyaman Training and Research Hospital, Adiyaman, Turkey. ${ }^{2}$ Department of Otorhinolaryngology, Adiyaman Training and Research Hospital, Adiyaman, Turkey. ${ }^{3}$ Department of Neurosurgery, Adiyaman Training and Research Hospital, Adiyaman, Turkey. ${ }^{4}$ Department of Radiology, Adiyaman Training and Research Hospital, Adiyaman, Turkey.

Received: 1 May 2021 Accepted: 12 Auqust 2021

Published online: 30 August 2021

\section{References}

1. Oiticica J, Bittar RS. Tinnitus prevalence in the city of Sao Paulo city. Braz J Otorhinolaryngol. 2015;81(2):167-76.

2. Davis A, Rafaie AE. Epidemiology of tinnitus. In: Tyler RS, editor. Tinnitus handbook. San Diego: Singular Thomson Learning; 2000. p. 1-23.

3. Hasson D, Theorell T, Wallén MB, Leineweber C, Canlon B. Stress and prevalence of hearing problems in the Swedish working population. BMC Public Health. 2011;11:130.

4. Canlon B, Theorell T, Hasson D. Associations between stress and hearing problems in humans. Hear Res. 2013;295:9-15.

5. Elgoyhen $A B$, Langguth $B$, Ridder DD, Vanneste $S$. Tinnitus: perspectives from human neuroimaging. Nat Rev Neurosci. 2015;16(10):632-42.

6. Datzov E, Danev S, Haralanov H, Naidenova V, Sachanska T, Savov A. Tinnitus, heart rate variability, and some biochemical indicators. Int Tinnitus J. 1999;5(1):20-3.

7. Miyoshi S, Eng M, Uemi N, Eng D, Ifukube T. Increased parasympathetic nerve tone in tinnitus patients following lectrical promontory stimulation. Int Tinnitus J. 1996;2:67-71.

8. Ozturk M, Turan OE, Karaman K, Bilge N, Ceyhun G, Aksu U, et al. Evaluation of ventricular repolarization parameters during migraine attacks. J Electrocardiol. 2019;53:66-70.

9. Yamaguchi M, Shimizu M, Ino H, Terai H, Uchiyama K, Oe K, et al. T wave peak-to-end interval and QT dispersion in acquired long QT syndrome: a new index for arrhythmogenicity. Clin Sci. 2003;105(6):671-6.

10. Lubinski A, Lewicka NE, Kempa M, Baczynska AM, Romanowska I, Swiatecka G. New insight into repolarization abnormalities in patients with congenital long QT syndrome: the increased transmural dispersion of repolarization. Pacing Clin Electrophysiol. 1998;21(1 Pt 2):172-5.

11. Castro TY, Carmona PR, Katholi RE. Ventricular repolarization markers for predicting malignant arrhythmias in clinical practice. World J Clin Cases. 2015:3:705-20.

12. Lu HR, Yan GX, Gallacher DJ. A new biomarker-index of cardiac electrophysiological balance (iCEB) plays an important role in drug-induced cardiac arrhythmias: beyond QT-prolongation and Torsades de Pointes (TdPs). J Pharmacol Toxicol Methods. 2013;68(2):250-9.

13. Robyns T, Lu HR, Gallacher DJ, Garweg C, Ector J, Willems R, et al. Evaluation of Index of Cardio-Electrophysiological Balance (iCEB) as a new biomarker for the identification of patients at increased arrhythmic risk. Ann Noninvasive Electrocardiol. 2016;21(3):294-304.

14. Bazett HC. An analysis of the time relationships of electrocardiograms. Ann Noninvasive Electrocardiol. 2006;2(2):177-94.

15. Lang RM, Bierig M, Devereux RB, Flachskampf FA, Foster E, Pellikka $\mathrm{PA}$, et al. Chamber Quantification Writing Group; American Society of Echocardiography's Guidelines and Standards Committee; European Association of Echocardiography. Recommendations for chamber quantification: a report from the American Society of Echocardiography's Guidelines and Standards Committee and the Chamber Quantification Writing Group, developed in conjunction with the European Association 
of Echocardiography, a branch of the European Society of Cardiology. J Am Soc Echocardiogr. 2005;18(12):1440-63.

16. Schiller NB, Shah PM, Crawford M, DeMaria A, Devereux R, Feigenbaum $\mathrm{H}$, et al. Recommendations for quantitation of theleft ventricle by twodimensional echocardiography: AmericanSociety of Echocardiography Committee on Standards, Subcom-mitteeon Quantitation of Two-Dimensional Echocardiograms. J Am Soc Echocardiogr. 1989;2:358-67.

17. Eggermont JJ, Roberts LE. The neuroscience of tinnitus. Trends Neurosci. 2004:27(11):676-82

18. Sahley TL, Nodar RH. A biochemical model of peripheral tinnitus. Hear Res. 2001;152(1-2):43-54.

19. Schmitt C, Patak M, Kröner-Herwig B. Stress and the onset of sudden hearing loss and tinnitus. Int Tinnitus J. 2000;6(1):41-9.

20. Baigi A, Oden A, Almlid-Larsen V, Barrenäs ML, Holgers KM. Tinnitus in the general population with a focus on noise and stress: a public health study. Ear Hear. 2011;32(6):787-9.

21. Moller AR. Tinnitus: presence and future. Prog Brain Res. 2007;166:3-16.

22. Herring N, Kalla M, Paterson DJ. The autonomic nervous system and cardiac arrhythmias: current concepts and emerging therapies. Nat Rev Cardiol. 2019;16(12):707-26

23. Evrengül H, Dursunoglu D, Cobankara V, Polat B, Seleci D, Kabukçu S, et al. Heart rate variability in patients with rheumatoid arthritis. Rheumatol Int. 2004;24(4):198-202.

24. Yorgun H, Canpolat U, Aytemir K, Ateş AH, Kaya EB, Akdoğan A, et al. Evaluation of cardiac autonomic functions in patients with systemic lupus erythematosus. Lupus. 2012;21(4):373-9.

25. Choi EJ, Yun Y, Yoo S, Kim KS, Park JS, Choi I. Autonomic conditions in tinnitus and implications for Korean medicine. Evid Based Complement Alternat Med. 2013;2013:402585.

26. Loo E, Congedo M, Vanneste S, Heyning PVD, Ridder DD. Insular lateralization in tinnitus distress. Auton Neurosci. 2011:165(2):191-4.

27. Betz LT, Mühlberger A, Langguth B, Schecklmann M. Stress reactivity in chronic tinnitus. Sci Rep. 2017;7:41521.

28. Kayıkcıoglu M, Payzın S. Heart rate variability. Turk Kardiyol Dern Ars. 2001;29(4):238-45.

29. Antzelevitch C, Sicouri S, Di Diego JM, Viskin S, Burashnikov A, Shimizu $S$, et al. Does Tpeak-Tend provide an index of transmural dispersion of repolarization? Heart Rhythm. 2007:4(8):1114-6.

30. Gupta P, Patel C, Patel H, Narayanaswamy S, Malhotra B, Green JT, et al. T(p-e)/QT ratio as an index of arrhythmogenesis. J Electrocardiol. 2008;41(6):567-74.
31. Sökmen E, Özbek SC, Çelik M, Sivri S, Metin M, Avcu M. Changes in the parameters of ventricular repolarization during preapnea, apnea, and postapnea periods in patients with obstructive sleep apnea. Pacing Clin Electrophysiol. 2018;41(7):762-6.

32. Arısoy A, Karaman K, Karayakalı M, Demirelli S, Seçkin HY, Çelik A, et al. Evaluation of ventricular repolarization features with novel electrocardiographic parameters (Tp-e, Tp-e/QT) in patients with psoriasis. Anatol J Cardiol. 2017;18(6):397-401.

33. Açar B, Yüksel M, Yayla Ç, Kırbaş Ö, Ünal S, ErtemAG, et al. Parameters of ventricular repolarization in patients with autoimmune hepatitis. Turk Kardiyol Dern Ars. 2017;45(4):333-8.

34. Lecca LI, Portoghese I, Mucci N, Galletta M, Meloni F, Pilia I, et al. Association between work-related stress and QT prolongation in male workers. Int J Environ Res Public Health. 2019;16(23):4781.

35. Afsin A, Asoğlu R, Orum MH, Cicekci E. Evaluation of TP-E interval and TP-E/QT ratio in panic disorder. Medicina (Kaunas). 2020;56(5):215.

36. Kaya H, Barutçu S. Gastroesophageal reflux disease is associated with abnormal ventricular repolarization indices. Turk J Gastroenterol. 2019;30(12):1021-4.

37. Shargorodsky J, Curhan GC, Farwell WR. Prevalence and characteristics of tinnitus among US adults. Am J Med. 2010;123(8):711-8.

38. Cakici M, Dogan A, Cetin M, Suner A, Caner A, Polat M, et al. Negative effects of acute sleep deprivation on left ventricular functions and cardiac repolarization in healthy young adults. Pacing Clin Electrophysiol. 2015;38(6):713-22.

39. Nafakhi H, Al-Mosawi AA, Alareedh M, Al-Nafakh HA. Index of cardiac electrophysiological balance and transmural dispersion of the repolarization index relationships with pericardial fat volume and coronary calcification. Biomark Med. 2018;12(4):321-8.

40. Yumurtacı O, Kurt C, Ucar FM, Ozturk C. Usefulness of electrocardiographic markers to predict ventricular arrhythmia in acute myocarditis. Turkish Med Stud J. 2017;4:6-10.

\section{Publisher's Note}

Springer Nature remains neutral with regard to jurisdictional claims in published maps and institutional affiliations.
Ready to submit your research? Choose BMC and benefit from:

- fast, convenient online submission

- thorough peer review by experienced researchers in your field

- rapid publication on acceptance

- support for research data, including large and complex data types

- gold Open Access which fosters wider collaboration and increased citations

- maximum visibility for your research: over $100 \mathrm{M}$ website views per year

At BMC, research is always in progress.

Learn more biomedcentral.com/submissions 